American Journal of Environmental Sciences 3 (1): 30-36, 2007

ISSN 1553-345X

(C) 2007 Science Publications

\title{
Environmental Issues in Jordan, Solutions and Recommendations
}

\author{
Nidal A. Hadadin and Zeyad S. Tarawneh \\ Department of Civil Engineering, The Hashemite University, P.O. Box 150459, Zarqa 13115, Jordan
}

\begin{abstract}
Jordan's natural resources are limited to support population in a sustainable manner. However, its environment is exposed to a number of threats. In order to best explain Jordan's environmental difficulties, it would be prudent to focus individually on each of these major concerns: water shortages, agriculture/land and air pollution. This study focuses on the environmental problems in Jordan and has addressed the process of reversing environmental decline. A true foundation of environmental protection requires awareness upon the part of the population and a number of governmental and non-governmental organizations are actively involved in educating the populace about environmental issues. This article presents specific recommendations addressing water resources, the areas of agriculture and air pollution. It emphasis throughout on the conservation of water, agriculturally productive land and the quality of air, of which, the contamination or loss of them would bring rapid and significant consequences to Jordan.
\end{abstract}

Key words: Water shortages, agriculture, land use, air pollution

\section{INTRODUCTION}

Jordan was a country relatively free of environmental problems until the 1970s. As a result of modernization and population increase, the environment problems arise. The rapidly increasing in population began to use more water than the country could provide. Additionally, urbanization became a great source of contamination of the air and the environment. Development of land, necessary to industrialization, began to violate the country's wildlife habitats. Soil erosion simultaneously became a prevalent issue, as the country realized the effects of years of agriculture and logging upon the land. All of these potential environmental emergencies came to a head throughout the 1970s and the 1980s, causing a great deal of attention and concern to be cast upon various major problems in need of remedy ${ }^{[1]}$.

The greatest environmental challenge that Jordan faces today is the scarcity of water. Indeed, water is the decisive factor in the population/resources equation. A high rate of natural population growth, combined with periodic massive influxes of refugees, has transformed a comfortable balance between population and water.

The situation has been exacerbated by the fact that Jordan shares most of its surface water resources with neighboring countries, whose control has partially deprived Jordan of its fair share of water. Current use already exceeds renewable supply. The deficit is covered by the unsustainable practice of overdrawing highland aquifers, resulting in lowered water tables and declining water quality. On a per capita basis, Jordan has one of the lowest levels of water resources in the world.

Water Shortage $^{[2]}$ : The country does not have regional or local rivers; the Jordan River is polluted and saline and runs almost dry most of the year. Around $90 \%$ of the country receives average precipitation of less than $100 \mathrm{~mm} / \mathrm{year}$ and is generally classified as arid. The eastern desert areas receive as little as $50 \mathrm{~mm}$ per year. Only 3\% of Jordan's land receives average annual precipitation of more than $300 \mathrm{~mm}$.

The scarcity and uneven distribution of precipitation over Jordan results in limited surface and groundwater resources available for domestic consumption and agricultural and industrial uses. Rapid population growth coupled with increased urbanisation and industrialisation are leading to the over-exploitation of aquifers and the contamination of diminishing supplies through: Inadequate industrial and municipal wastewater treatment capacities; Sitting of industrial plants near or immediately upstream from potable supplies; and Overuse and misuse of pesticides, insecticides, fungicides and fertilisers leading to pollution of ground and surface water resources by irrigation drainage.

Jordan, which carries the same name as River Jordan, has very little water from river resources because rivers and streams are drying out. Therefore, Jordan mainly depends on rainfall, which is around 200 $\mathrm{mm}$ per year. Jordan is known to have a large area of desert land on its eastern borders with Iraq and Saudi Arabia.

Corresponding Author: Nidal A. Hadadin, Assistant Professor, Department of Civil Engineering, The Hashemite University, P.O. Box 150459, Zarqa 13115, Jordan 
The Jordanian Government claims that in comparison to some of Jordan's neighbours, the Kingdom's population have far less water per head of population. While a Jordanian in 1993 had an annual water share of 240 cubic metres (CM), an Egyptian averaged 1,200, a Syrian 1,450 and Israeli 450 cubic meters. In the capital Amman, water needs have risen to $300,000 \mathrm{CM} /$ day. This is $90,000 \mathrm{CM}$ more than the maximum available daily water levels, a deficit of 35 million cubic metres (MCM) a year. Such severe water shortages have forced the government to impose a rationing programme, whereby domestic supply is pumped twice a week during summer months. The future prospects for water availability are not good. Jordan's population is expected to rise to 7.3 million by the year 2010 and the resulting gap between water supply and demand is expected to widen significantly. At the forefront of Jordan's present environmental problems is that of water. Meanwhile, climactic changes have lessened the rainfall, a natural force upon which the Jordanians depend for an increase of surface water levels and the feeding of renewable underground resources. The lack of rain has had adverse effects upon the country's amount of surface water and heightened public water consumption has only served to aggravate this situation.

Being a topic of much consternation, the Jordanian water shortages are a threat both to development and to the health of the population. Jordan has a multi-faceted difficulty with its lack of available water resources. Over the past decades, there have been extreme changes in climate that have drastically affected Jordan's water supply - the depleting ozone layer is said to be a potential cause for Jordan's shorter rainy seasons and lower rain levels - in 1987/88 Jordan received 12, 252 MCM, while in $1989 / 90$, the country only received 7 , 609 MCM of rain

Overall, though, it is the high water consumption level of the Jordanian people, for agriculture in particular, but also for industrial and domestic use that has endangered the country's water supply and caused so many shortages. In 1995 Jordan consumed 983 MCM of water, which is a number 49 percent greater than the country's renewable water resources. Additionally, water usage in Amman, the capital city, has reached levels of $300,000 \mathrm{~cm}$ per day - exceeding the maximum available daily levels by $90,000 \mathrm{~cm}$ and yielding a yearly water deficit of $35 \mathrm{MCM}$ a year.

As a result of this excess, Jordan's water sources have been drained and dried, as well as polluted, over and over again.

Evaluating water balances in Jordan $\left(\mathrm{PRB}^{[3]}\right)$ : Jordan has endured deficits in water resources since the early 1960s. The country is classified as water scarce. Renewable annual freshwater available per person is $327 \mathrm{~m} 3$ per year, its rank is number ten in the world concerning the insufficiency in water.
Table 1: Aquifer and basin water status in Jordan $\left(\mathrm{Mm}^{3} /\right.$ year $)$

\begin{tabular}{lcc}
\hline Basin & Used & Available \\
\hline Yarmouk & 59 & 40 \\
Jordan River tributaries & 6.3 & 15 \\
Jordan River plains & 21.7 & 21 \\
Amman and Zarqa & 153.8 & 57 \\
Dead Sea & 68.6 & 57 \\
Diesa & 56 & 100 \\
North Wadi Araba & 1.75 & 3.5 \\
South Wadi Araba & 4 & 5.5 \\
Jaffar & 23 & 27 \\
Azraq & 32 & 28 \\
Sarhan & 0.8 & 5 \\
Hamad & 1.8 & 8
\end{tabular}

Table 2: Water resources: ground, surface and nontraditional $\left(\mathrm{Mm}^{3}\right)$

Renewable groundwater 280

Nonrenewable groundwater $\quad 118$

Surface water

118
755

Treated wastewater

22

Table 3: Water usage in Jordan, 1985-2005 $\left(\mathrm{Mm}^{3}\right)$

\begin{tabular}{llllc}
\hline Sector & 1985 & 1989 & 1995 & 2005 \\
\hline Domestic & 200 & 242 & 254 & 301 \\
Agricultural & 624 & 721 & 877 & 1066 \\
\hline
\end{tabular}

\begin{tabular}{lccc} 
Table 4: & \multicolumn{3}{c}{ Population versus per capita water availability } \\
\hline year & $\begin{array}{l}\text { Total annual } \\
\text { renewable fresh water } \\
\text { available (Mm3) }\end{array}$ & $\begin{array}{l}\text { Population } \\
\text { (millions) }\end{array}$ & $\begin{array}{l}\text { Per capita water } \\
\text { availability (m3) }\end{array}$ \\
\hline 1955 & 1331 & 1.447 & 920 \\
1990 & 906 & 4.009 & 226 \\
2020 & 1236 & 10.229 & 120 \\
\hline
\end{tabular}

Jordan's primary sources of water are aquifers and basins (Table 1) fed and recharged through annual rainfall. The Yarmouk Basin is the largest in the country. Jordan's water supply suffers because about $85 \%$ of the total amount of water is lost to evaporation annually, which leaves only a small amount of surface and groundwater to enter the water supply. Table 2 shows Water resources: ground, surface and nontraditional $\left(\mathrm{Mm}^{3}\right)$.

Many methods have been suggested to increase the water supply, including intensive capturing of rainwater through the use of micro- and macro- dams, desalination of sea water and importation of water from neighboring countries, as well as other alternatives. However, all these are subject to cost-benefit analyses and geopolitical constraints.

Demand for water in Jordan: Water in Jordan is used primarily for agriculture (Table 3). Agriculture accounts for $77.5 \%$ of all water consumed, the rest being for domestic and industrial use. Annual growth in demand for water in Jordan is estimated at 25 $\mathrm{Mm}^{3} /$ year. This growth is related to urbanization and industrial expansion, as well as to increased domestic use, mainly as a result of population growth (Table 4).

The current situation of water supply and demand in Jordan raises serious concerns about the country's water balance, as well as about the qualitative 
Am. J. Environ. Sci. 3 (1): 30-36, 2007

Table 5: Water resources in Jordan, 1985-2005 $\left(\mathrm{Mm}^{3}\right)$

\begin{tabular}{|c|c|c|c|c|c|c|c|c|}
\hline \multirow[t]{2}{*}{ Year } & \multicolumn{2}{|c|}{1985} & \multicolumn{2}{|c|}{1989} & \multicolumn{2}{|c|}{1995} & \multicolumn{2}{|c|}{2005} \\
\hline & A & $\mathrm{C}$ & A & $\mathrm{C}$ & A & $\mathrm{C}$ & A & $\mathrm{C}$ \\
\hline Renewable groundwater & 280 & 313 & 280 & 375 & 280 & 359 & 280 & 390 \\
\hline Nonrenewable groundwater & 118 & 25 & 118 & 56 & 118 & 118 & 118 & 118 \\
\hline Surface water & 466 & 466 & 500 & 500 & 594 & 594 & 755 & 755 \\
\hline Treated wastewater & 20 & 20 & 32 & 32 & 60 & 60 & 60 & 60 \\
\hline
\end{tabular}

Note: $\mathrm{A}=$ available $; \mathrm{C}=$ consumed

deterioration of water. The picture is so gloomy that any water researcher would observe that it is all too easy for the country to "cross the red line" when faced with annual water deficits, overuse, resource depletion or contamination. Projections of water resources (Table 5) demonstrate that there will be persistent shortage.

Jordan River: The river Jordan, so famous in history and religion, is now nothing more than a creek. By the time that long-suffering stream reaches its end, most of the water has disappeared into a wide variety of pipes, pumps and fields to sustain the ever growing demands of the human population in its vicinity. The reasons for the shrinking of the Jordan reflect the overwhelming problem of the whole region in obtaining sufficient water ${ }^{[4]}$.

The Kingdom has three major rivers, the Jordan, the Zarqa and the Yarmouk. The Jordan River is saline and thus not directly suitable for drinking or irrigation. The River Zarqa receives substantial municipal, industrial and agricultural effluent rendering it unsuitable for domestic or irrigation uses in the dry season. Only during flood periods does the water quality improve. Though the River Yarmouk is reportedly less stressed, it is also a sink for municipal wastewater ${ }^{[5]}$.

Other surface waters affected by pollution are wadis, creeks, rivers and dams lying downstream from wastewater treatment plants and solid waste disposal sites .The King Talal Dam reservoir, Jordan's largest surface reservoir, is threatened by factories, which emit untreated waste into the reservoir's tributaries, raising salinity and levels of chemical and metal. In addition, many wadis are dammed so that their waters collect in reservoirs. These reservoirs are reported to be highly euthrophic. Groundwater salinisation and agricultural residues also influence surface waters ${ }^{[6]}$.

Two of the major sources of Jordan's surface water are the Jordan River and the Yarmouk River, both of which have been depleted by upstream diversion and over-pumping in Syria and Israel. Furthermore, Jordan's main aboveground reservoir, the Kink Talal Dam, is not a dependable long-term water source ${ }^{[7]}$.

The chaotic nature of the surface water levels frequently minimizes levels of trapped water, sometimes reducing them to below the dam's holding capacity of $86 \mathrm{MCM}$. Meanwhile, pollution has played a role in these reduced water supply levels as factories dispose of untreated waste materials in the tributaries leading to the dam - and the Jordanian population will not benefit from the use of a water supply with raised levels of chemicals and metals. Gideon reported average concentrations of toxic elements in sediments of the King Talal Reservoir from data compiled from reservoir suspended sediment annual reports. In the same study, selected boreholes (water wells) in the Amman-Zarqa catchments area in 1990 showed heavy contamination with TDS, $\mathrm{Na}, \mathrm{Cl}$ and $\mathrm{NO}_{3}{ }^{[6]}$. Other sources of water for Jordan include aquifers of limited potential, such as the now nearly depleted Azraq Oasis that supplies Amman.

DISI water conveyance project: The Disi-Mudawarra to Amman Water Conveyance System project has been conceived by the Water Authority of the Ministry of Water and Irrigation. The main objective is to convey additional water to the Greater Amman Area from the Disi Aquifer.

The Disi-Mudawarra to Amman Water Conveyance System will result in a reliable water supply to Amman especially during the summer. This project has been on the shelf for many years, postponed due to a lack of funding. However, due to pressing water needs, serious efforts have been made to implement the proposal. Disi is a fossil water aquifer extending from the southern edge of the Dead Sea in Jordan to Tabuk in northwest Saudi Arabia. At present Aqaba city is provided with $16.5 \mathrm{MCM}$ for domestic purposes and $75 \mathrm{MCM}$ for agricultural purposes. At present, the drinking water for Amman is supplied mainly from the upland aquifers and new developed aquifers to the south such as Lajoun Aquifer. An important aspect of the Disi project is that its implementation will secure an additional source of drinking water to Amman and thus relieve the upland aquifers from over-use. The Disi project will have an indirect effect on the quality of wastewater which in turn will lead to better quality water to be used for irrigation as a replacement for valuable freshwater.

Drop in dead sea level ${ }^{[8]}$ : Dead sea is a salt lake in southwestern Asia. Bounded on the west by Israel and the West Bank and on the east by Jordan, the Dead Sea forms part of the Israeli-Jordanian border. It is the lowest water surface on earth. Its top layer contains 
about $290 \mathrm{~g}$ of dissolved salts/liter and bottom layer $320 \mathrm{~g} / \mathrm{l}$. The level of the Dead Sea has been continuously dropping since the late fifties; from about $392 \mathrm{~m}$ below sea level in 1958 to about $411 \mathrm{~m}$ below sea level in 1998. The Lake is $80 \mathrm{~km}(50 \mathrm{mi})$ long and has a maximum width of $18 \mathrm{~km}(11 \mathrm{mi})$; its area is $1,020 \mathrm{sq}$ km (394 sq mi).

The Dead Sea is fed mainly by the Jordan River, which enters the lake from the north. Several smaller streams also enter the sea chiefly from the east. The reason for this drop is the extensive exploitation of water resources, which formally used to flow into the Dead Sea. The water balance of the Dead Sea has since the late 1950s been disturbed and evaporation losses have been partly compensated by reducing amount of ground water. The lake has no outlet and the heavy inflow of fresh water is carried off solely by evaporation, which is rapid in the hot desert climate. Due to large-scale projects by Israel and Jordan to divert water from the Jordan River for irrigation and other water needs, the surface of the Dead Sea has been dropping for at least the past 50 years ${ }^{[9]}$.

\section{Precipitation at the surface of the dead sea average} $100 \mathbf{m m}$. Since the DS has no outflow, it forms an ultimate base level for both surface and groundwater. The only water loses are caused by evaporation. Therefore, on an average, the amount of incoming water must be equal to the amount of evaporation but the actual evaporation was calculated and found to be $2651 \mathrm{~mm} / \mathrm{yr}^{[10]}$.

The level of the Dead Sea is subjected to different types of changes caused by formational, climatic and humanistic reasons. These changes can be summarized as follows:

* Changes caused by arising and vanishing of civilizations in the Dead Sea catchment area, because each of these civilizations used the surface water resource for irrigation and hence reduced the amount of water flowing to the Dead Sea and therefore caused a drop in the level.

* Seasonal change due to the inflow of floodwater in the rainy season and loss of water due to high evaporation rates in the dry season, throughout its history the Dead Sea level was subjected to these three types of changes.

* During the last four decades large water projects have been carried out in the catchment area utilizing about $60 \%$ of the water sources formerly were draining to the Dead Sea (dams, diversions, etc).

* The Need of Sustaining Certain Water Level of the Dead Sea

The following points indicate the necessity to sustain the water level of the Dead Sea:

* The Dead Sea is a tourist attraction surrounded by numerous tourists' facilities. Any drop in sea level, leaves these facilities far away from the shoreline, which contradicts the reason for their existence. Also any rise in water level above the baseline of these facilities would mean their flooding and their demolition.

* The drop of the sea level below a certain level would mean pumping cost for the potash works. These works must work economically; therefore they have their optimal rise in the sea level. Also the cause of any rise in sea level above a certain limit would mean flooding of existing facilities.

The water level should be sustained and account for the following:

* Optimal operation costs for potash works.

* Tourist facilities should remain at the shores

* They should not be away from them and should not be over flooded by any sea level

* Irrigated agricultural land should also not be over flooded

* Roads, bridges and other constructions should remain unaffected by raising the sea level

Considering the above-mentioned aspects, a water level of 395 BSL should be the most appropriate level for all partners ${ }^{[8]}$.

Water sources to sustain the dead sea level: Since no natural water sources within the Dead Sea catchment area can be made available to sustain an optimal Dead Sea level to fulfill the above aspects, Red Sea -Dead Sea canal was introduced to bring water to the Dead Sea.

Water from the Red Sea through a canal along Wadi Araba utilizing the differences in levels between both seas for energy production, construction some fish pools along the canal and utilizing the water for cooling and other mining projects.

Present amount of water flowing into the dead sea: Since about 30 years large projects utilizing surface and ground water, which formerly discharged into the Dead Sea, have been implemented. These diverted and dammed water sources caused during the last 30 years a continuous drop in Sea level. The utilized surface water is:

* About $500 \mathrm{MCM} / \mathrm{yr}$ is diverted from the upper Jordan river reach outside the Dead Sea catchment by Israel.

* The greatest portion of the water sources west of the Jordan valley $(52 \mathrm{MCM} / \mathrm{yr})$ is utilized. Only a small part not exceeding $6 \mathrm{MCM} / \mathrm{yr}$. still flow as floods to the Dead Sea via Jordan River.

* The east Ghor Canal utilized about $100 \mathrm{MCM} / \mathrm{yr}$

* Dams in Jordan at the eastern side the Jordan River store about $100 \mathrm{MCM}$

* Along the West Side of the Dead Sea only negligible amounts of surface still find their way to the DS. About $150 \mathrm{MCM} / \mathrm{yr}$ are utilized.

* About $15 \mathrm{MCM} / \mathrm{yr}$ are used along the eastern side of the Dead Sea. 
* Only negligible amounts of the groundwater flowing to the DS from its eastern side are utilized. $50 \mathrm{MCM} / \mathrm{yr}$ are extracted from the groundwater flowing to the Dead Sea from the western side. Only about $50 * \quad \mathrm{MCM} / \mathrm{yr}$ still flow into the Dead Sea.

* The major part of the water resources of wadi Araba of about $50 \mathrm{MCM} / \mathrm{yr}$ with in the Dead Sea catchment is extracted.

* About $20 \mathrm{MCM} / \mathrm{yr}$ out of $30 \mathrm{MCM} / \mathrm{yr}$ are used east of wadi Araba within the Dead Sea catchment.

* The total extraction of surface and ground water sources formerly flowing into the DS equal 1095 MCM.

Amount of water, which could be brought to bring about a recovery of the Dead Sea level:

* The yearly amount of evaporation at a sea level of -395 equals $1880 \mathrm{MCM}$. Only about $545 \mathrm{MCM} / \mathrm{yr}$ are still flowing into the Dead Sea. Therefore a yearly amount of $1335 \mathrm{MCM}$ can still be accommodated without causing any additional rise in water level.

Agriculture/land: Agriculture has been dramatically impaired as a result of soil erosion and urbanization has served to destroy many of the land resources, including plants and trees, that are native to the Jordanian climate. Also, the use of agricultural chemicals has combined with the random discarding of plastics and other hazardous wastes that pollute the agricultural environment and make static the agricultural production system in the country.

In addition to decreased precipitation, increasing desertification, a process in which human activities leech the soil of its nutrients and effectively make it agriculturally barren, has aggravated the water problems, as well as leading to a higher national rate of poverty as farmers are left without crops and therefore without revenues.

The non-availability of approved national land use plans is identified as major factor contributed to: unacceptable interaction between industrial zones and urban zones, also, inability to combat the permanent damage to agricultural lands which are being converted into urban areas.

Aside from the water crisis, however, Jordan does have many other environmental problems - not the least of which is difficulties with the land as a result of agriculture, as well as the suffering of agriculture due to urbanization and modernization. As aforementioned, desertification has led to a great deal of soil erosion, as land is used and reused for agricultural and other purposes, as logging and other clearing activities occur and as animals are overgrazed on the land, preventing the soil from regenerating as it normally would. The challenge of desertification is one to the economy of Jordan, as poverty and unemployment rates are directly related to amount and quality of land.
Deforestation comes into play here - in this process, trees are cut down to provide space for land cultivation, urbanization and industrial uses of the wood. Along with removing environmentally valuable vegetation from the land, deforestation causes the loosening and removal of the most fertile part of the soil, the topsoil. The nutrients of the soil are thereby depleted and agriculture yields crops of inferior quality. With such a damaged soil structure, flooding becomes a threat to the land and to the wildlife, throwing off the balance of the ecosystem.

Agriculture consumes between 75 and 90 percent of water in Jordan. At the same time, agricultural practices and cultural values frequently have combined to produce water shortages. In addition, most Middle Eastern states emphasize the development of industry and manufacturing and have allowed agricultural wages to lag so far behind other sectors "only the very young, the very old and the unemployable are involved in food production. Land reform has generally been ineffective, while outdated and ineffective irrigation systems, such as open canals and surface irrigation, are prevalent.

Because of water scarcity, generally arid conditions and poor or outdated technologies for delivering available water, agriculture has failed to meet increasing demands placed on it by expanding populations. As a consequence, the Middle East is rapidly becoming one of the least agriculturally selfsufficient regions in the world, a trend that is destabilizing in the extreme in an area where little regional trade is conducted and where great, if not disproportionate, value is put on self-sufficiency. Governments are wary of dependency on food imports because of the heavy financial burdens they entail and the potential for strategic vulnerability that they imply. National security thus translates into food security and food security translates into water security.

Much effort has been expended to increase the availability of water resources for irrigation and water reuse, but broad extension of current systems will require major investment of already scarce capital, in addition to meeting escalating costs of construction and maintenance that would not necessarily be offset by rising agricultural prices. As water scarcities increase, food production is declining in relation to an annual 2-4 percent increase in demand. For the most part, Middle Eastern governments are not able to fully support growing populations that are expected to double within the next 20 years.

Air pollution: Animal, plant and human population of the country are affected by air pollution from industries, automobiles and sand and dust storms from North Africa enhance the smog and contamination of the country's atmosphere.

Air pollution in the urban environment is caused by; high sulfur content of fuel, use of leaded petrol and low efficiency of cars, increasing number of vehicles, 
excessive energy consumption, inefficient transport storing and utilizing of building materials and smells from uncontrolled wastes, congested sewerage systems and waste treatment plants.

The air is considered relatively clean in most of the country except for some polluted areas such as Amman, Zarqa and Faheis. The major sources include: Stationary sources such as manufacturing plants, refineries, mines, gas stations and domestic areas; Mobile sources such as Jordan's estimated 400,000 vehicles that use gasoline and diesel oil, aeroplanes, ships and trains; and natural sources such as sand and dust storms. Meteorological Department statistics indicate that five to six Khamasini depressions (hot, windy and dusty conditions) from the North African coast occur yearly and dust resulting from them, amounts to 1.8 million tons/year .

In Amman, transport is a major source of gaseous pollution. The high annual averages of total suspended particulates, sulphur dioxide, carbon monoxide and nitrogen oxides, in Amman regularly exceed World Health Organisation air quality standards ${ }^{[11]}$.

\section{CONCLUSION}

Jordan's environmental situation significant changes over the centuries and continues to be threatened by a number of factors. A rapidly expanding population, industrial pollution, Jordan's absorption of hundreds of thousands of people has resulted in the over-exploitation of many of its natural resources and the country's severe shortage of water has led to the draining of underwater aquifers and damage them.

This study presents some strategic initiatives for facilitating and institutionalizing long-term progress in the environmental sphere: Promotion of public awareness of and participation in environmental protection programs, construction of a comprehensive legal framework for environmental management, giving an expanded role for Jordan's protected areas, giving sectoral priority to water conservation and slowing Jordan's rapid population growth. Methods for follow up:

* Collect data and data bank

* Research and studies

* Setting priory based on cost- benefit analysis

* Step by step implementation process

* Funding support, training program, technique assistance

* Instrument (environmental models, vehicle inspection technique, emission measure technique, ect.),

* Public awareness through education, publicity (press, seminars, leaflets etc.)

* Organized land use planning

* Enforcement of safety regulations

* Executing a long-term responsibility to promote confidence for environmental policy
* Encourage active and future oriented research and development process,

* Working to minimize the consumption of energy and raw materials,

* Executing a sufficient network of environmental staffs, local environmental coordinates and specialist of various kinds

* Planning and performing environmental investigation, evaluating the results through application of investigations and broad knowledge of environmental problems

* Planning for urban monitoring network, air quality at urban site and outdoor measurements of air pollution.

\section{Recommendations}

* Developing a knowledge and informative package consisting of theoretical, technical and managerial solutions for the treatment and reuse of wastewater

* Monitoring of air pollution levels in the major cities in Jordan with Carbon Monoxide, Sulfur Dioxide, Nitrogen Oxides, hydrogen sulfide and Dust.

* Monitoring the seasonal and annual water quality variations in the reservoir of temperature variation with depth and heavy metals concentrations. The impact of water quality on the soil and the plants in Jordan Valley should be analyzed.

* Water quality analyses performance to evaluate the seasonal variations in water quality in the main reservoirs. For example, assessing the water quality in the major resources feeding King Abdullah Canal and Zai Treatment Unit and determining the seasonal fluctuations of the water quality.

* Assessing the existing water harvesting structures by hydrological studies, analytical tests and determining the sediments amount in these structures.

* Studying the treatment methods of industrial wastewater containing heavy metals by using lab scale model of physio-chemical treatment at the proper operating conditions.

* Utilizing the renewable energies as solar and went to operate small wastewater treatment plant in rural areas, or utilizing the biogas produced from anaerobic stabilization ponds as source of energy.

* Implementation of comprehensive environmental study as a part of the master plan, entailing and assessment of the existing state of surface and groundwater quality, air quality and the ecology of the area as a whole.

* To assess the level of water contamination caused by industrial activities, recommend a facility for the safe disposal of hazardous waste and determine the extend of soil and water contamination arising from the over use of herbicides and fertilizers in the Jordan Valley. 
* The concentration of hydrogen sulfide (H2S) at AlHashimiyeh town should be monitored to study the potential impacts of oil refinery, Hussein Thermal Station and Assamra treatment plant. The baseline data should be prepared to determine the possible measures to minimize the pollution impacts.

* Monitor industries and activities that cause air pollution and impose restrictions to protect air quality.

* Study the environmental impact of newly proposed industrial activities and plants.

* Prepare contingency plans for air pollution and define executive measures.

* Help select sites for industries, which emit air pollutants. Monitoring stations are placed at three major industrial locations in Jordan: Amman, Zarqa and Faheis.

\section{REFERENCES}

1. Irani, K. and C. Johnson, 2000. The Dana Project, Jordan. Parks, 10: 41-44.

2. Al-Jayyousi, O.R. and M.R. Shatanawi, 1995. An analysis of. Future water policies in Jordan using decision support. Systems. Wat. Resources Dev., 11: 315 .

3. Population Reference Bureau (PRB), 1998. World population data sheet. Demographic data and estimates for the countries and regions of the world. PRB, Washington, DC, USA.

4. Reguer, S., 1993. Controversial waters: Exploitation of the Jordan river, 1950-80. Middle Eastern Studies, 29: 53-90.
5. Abu-Taleb and F. Maher, 1994. Environmental management in Jordan: Problems and recommendations. Environmental Conservation, 21: 35-40.

6. Gideon, R., 1991. The potential impact of industrial wastes on water resources in AmmanZarqa basin. Proc. Sec. Environ. Poll. Symp. 1990. Friederich Ebert Stiftung Goethe-Institut, Amman Water Research and Study Center. University of Jordan, Amman.

7. Hof, F.F., 1995. The Yarmouk and Jordan rivers in the Israel-Jordan peace treaty. Middle East Policy, 3: 47-56.

8. Salameh, E. and H. El-Naser, 1999. Does the actual drop in the dead sea level reflect the development of water recourses within the drainage basin? Acta Hydrochim. Hydrobiol., 27: 5-11.

9. Steinhorn, I. and J.R. Gat, 1983. The Dead Sea. 249 Scientific American, 102: 102-9.

10. Kafri, U., 1982. Relationship between Dead Sea and ground water levels in the western Dead Sea catchment area. Geol. Surv. Isr. Curr. Res., pp: 9094.

11. Regional Euro-Mediterranean Programme for the Environment (SMAP) National Workshop Environmental Policy Integration and SMAP III Documentation References www.smaprms.Net 1997. 